ARTICLE

\title{
2,2-difluorovinyl benzoates for diverse synthesis of gem-difluoroenol ethers by Ni-catalyzed cross-coupling reactions
}

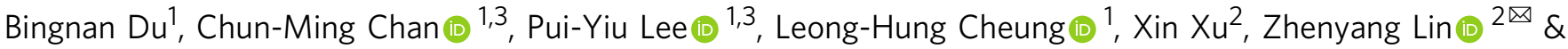 \\ Wing-Yiu Yu (i) ${ }^{1 凶}$
}

gem-Difluoroalkene is a bioisostere of carbonyl group for improving bioavailability of drug candidates. Herein we develop structurally diverse 2,2-difluorovinyl benzoates (BzO-DFs) as versatile building blocks for modular synthesis of gem-difluoroenol ethers (44 examples) and gem-difluoroalkenes ( 2 examples) by Ni-catalyzed cross coupling reactions. Diverse BzO-DFs derivatives bearing sensitive functional groups (e.g., $C=C$, TMS, strained carbocycles) are readily prepared from their bromodifluoroacetates and bromodifluoroketones precursors using metallic zinc as reductant. With $\mathrm{Ni}(\mathrm{COD})_{2}$ and dppf $\left[1,1^{\prime}\right.$-bis(diphenylphosphino)ferrocene] as catalyst, reactions of BzO-DFs with arylboronic acids and arylmagnesium/alkylzinc reagents afforded the desired gem-difluoroenol ethers and gem-difluoroalkenes in good yields. The Ni-catalyzed coupling reactions features highly regioselective $\mathrm{C}$ (vinyl)-O (benzoate) bond activation of the BzO-DFs. Results from control experiments and DFT calculations are consistent with a mechanism involving initial oxidative addition of the $\mathrm{BzO}-\mathrm{DFs}$ by the $\mathrm{Ni}(0)$ complex. By virtue of diversity of the $\mathrm{BzO}-\mathrm{DFs}$ and excellent functional group tolerance, this method is amenable to late-stage functionalization of multifunctionalized bioactive molecules.

\footnotetext{
${ }^{1}$ State Key Laboratory of Chemical Biology and Drug Discovery and Department of Applied Biology and Chemical Technology, The Hong Kong Polytechnic University, Hung Hom, Kowloon, Hong Kong. ${ }^{2}$ Department of Chemistry, The Hong Kong University of Science and Technology, Clear Water Bay, Kowloon, Hong Kong. ${ }^{3}$ These authors contributed equally: Chun-Ming Chan, Pui-Yiu Lee. ${ }^{\bowtie}$ email: chzlin@ust.hk; wing-yiu.yu@polyu.edu.hk
} 
em-Difluoroalkene functionality is considered as the bioisostere of a carbonyl group in drug design (Fig. 1a) ${ }^{1,2}$. Drug molecules containing carbonyl groups are prone to reduction by $\mathrm{NAD}(\mathrm{P}) \mathrm{H}$-dependent reductases, causing poor bioavailability owing to drug-inactivation and excretion ${ }^{3,4}$. Bonnet-Delpon and co-workers already demonstrated that gem-difluoroalkene-derivatized artemisinins exhibit prolonged in vivo antimalarial activity through replacement of the carbonyl group ${ }^{5}$. Moreover, gemdifluoroalkenes can be transformed to various organofluorine motifs $^{6,7}$ such as trifluoromethyl ${ }^{8-10}$, difluoromethyl ${ }^{11-14}$, monofluoroalkenyl ${ }^{15-18}$, and difluoromethylenyl ${ }^{19,20}$ groups for late-stage functionalization. Conventionally, Wittig- or Horner-WadsworthEmmons-type olefination and $\mathrm{S}_{\mathrm{N}} 2$ reactions of vinyl trifluoromethyl compounds are widely employed to construct the gem-difluoroalkene moiety ${ }^{7,21,22}$. However, development of new strategies for structurally diverse synthesis of the gem-difluoroenol ethers and gem-difluoroalkenes under mild conditions is highly desirable.

Transition metal-catalyzed defluorinative cross-coupling reactions are attracting considerable attention for the synthesis of structurally diverse gem-difluoroalkenes (Fig. 1b) ${ }^{23-26}$. For instance, $\mathrm{Hu}^{27}$ pioneered the $\mathrm{Cu}$-catalyzed defluorinative coupling of trifluoromethylsilane and diazoalkanes. Alternatively, transition metal-mediated aryl/alkylative allylic $\beta$-fluoride elimination of trifluoromethyl alkenes also demonstrates enormous promises in this pursuit. In 2008, Murakami and co-workers reported the first example of gem-difluoroalkenes synthesis by the Rh-catalyzed addition of arylboronic acids to $\alpha$-(trifluoromethyl) styrene, followed by $\beta$-fluoride elimination ${ }^{28}$. Later, the groups of Hayashi ${ }^{29}$ and Lautens ${ }^{30}$ independently developed the analogous $\mathrm{Rh}$-catalyzed asymmetric arylative $\beta$-fluoride elimination reactions. Recently, Ni-catalyzed defluorinative reductive cross-coupling of trifluoromethyl alkenes with $\mathrm{N}$-hydroxyphthalimide esters ${ }^{31}$, acetals ${ }^{32}$, cyclobutanone oxime esters ${ }^{33}$, and alkenes ${ }^{34}$ have been reported. Norton and co-workers demonstrated the hydrodefluorination reactions of $\mathrm{CF}_{3}$-substitited alkenes catalyzed by $\mathrm{Ni}(\mathrm{II})$-hydride complexes. The reaction was mediated by $\mathrm{H}$-atom transfer from $\mathrm{Ni}(\mathrm{II})$-hydride, followed by defluorination ${ }^{35}$.

While the current cross-coupling protocols are effective for the synthesis of gem-difluoroalkenes, other moieties such as gemdifluoroenol ethers which are also found in some pharmaceutical compounds remains less accessible ${ }^{36-40}$. In this regard, Katz and co-workers reported the preparation of stable potassium trifluoroborate gem-difluoroenol ethers, which would deliver the gem-difluoroenol ethers by cross-coupling with aryl halides under palladium catalysis ${ }^{41}$. To our knowledge, methods producing gem-difluorovinyl building blocks with immense structural diversity for the gem-difluoroenol ethers and gem-difluoroalkenes synthesis are rare. Herein we report a convenient synthesis of structurally diverse 2,2-difluorovinyl benzoates (BzO-DFs) by zinc treatment of the abundant bromodifluoroacetates and bromodifluoroketones as starting materials. The $\mathrm{BzO}-\mathrm{DF}$ s serve as versatile building blocks for synthesis of diverse gem-difluoroenol ethers and gem-difluoroalkenes by $\mathrm{Ni}$-catalyzed arylation and alkylation using nucleophiles such as arylboronic acids, arylmagnesium bromides, alkylzinc bromides, potassium alkyltrifluoroborates. Encouragingly, cross electrophile coupling reactions involving alkyl chlorides were also feasible under $\mathrm{Ni}$ catalysis (Fig. 1c). a)
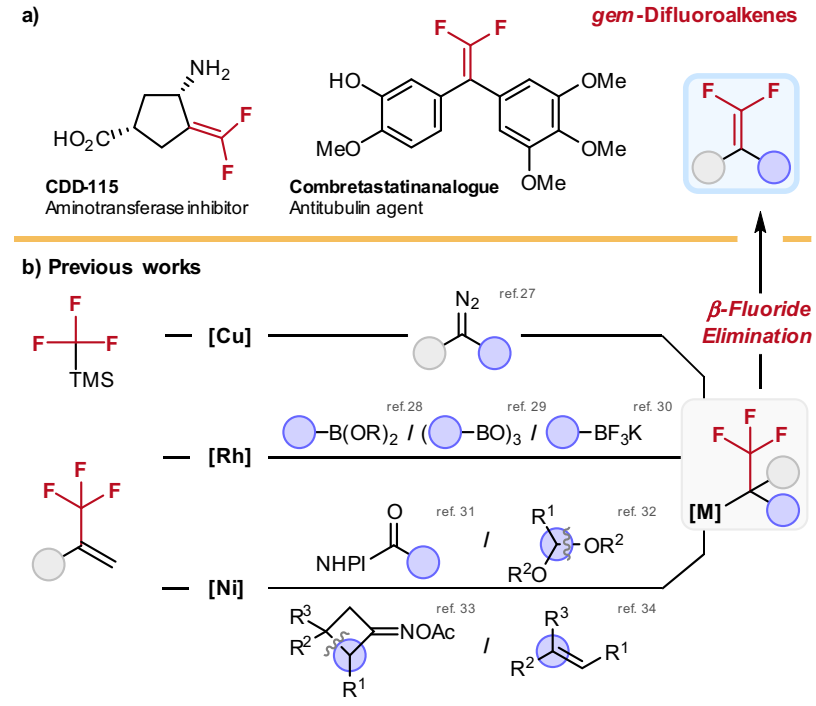

c) This work

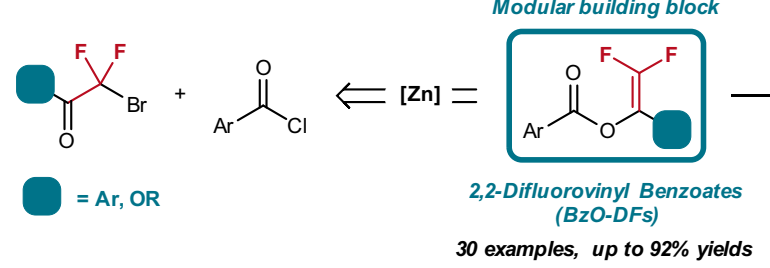

gem-Difluoroenol ethers
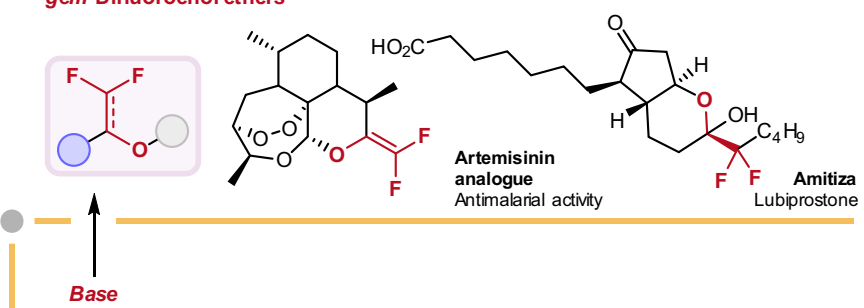

Elimination
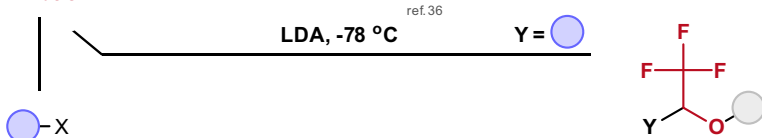

O-x

[Pd]
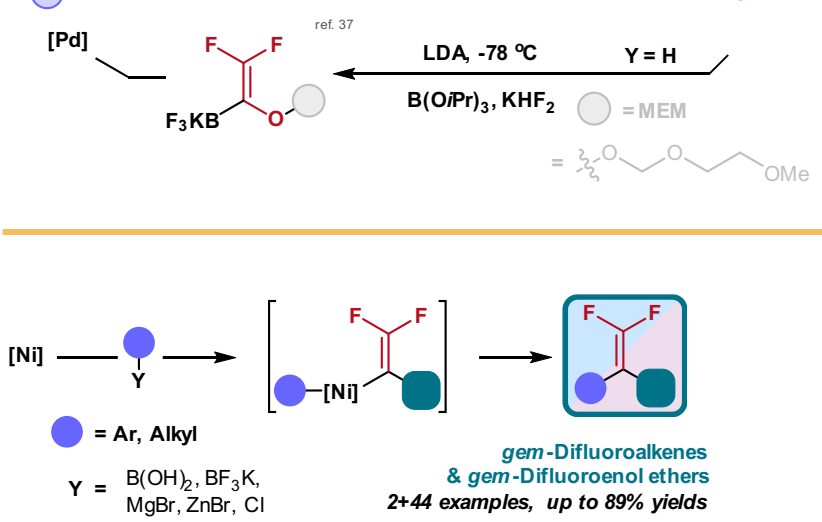

Fig. 1 Cross-coupling approaches toward gem-difluoroenol ethers and gem-difluoroalkenes synthesis. a Selected example of bioactive gem-difluoroenol ethers and gem-difluoroalkenes. b Conventional synthetic approaches for gem-difluoroenol ethers and gem-difluoroalkenes synthesis rely on $\beta$-fluoride elimination and base elimination as key steps; this approach demands tedious preparation of the trifluoromethyl-substituted precursors. c This work presents a convenient synthesis of 2,2-difluorovinyl benzoates (BzO-DFs) by simple zinc reduction of abundant bromodifluoroacetates and bromodifluoroketones; the BzO-DFs serve as versatile building blocks for Ni-catalyzed cross-coupling reaction for modular synthesis of gem-difluoroenol ethers and gem-difluoroalkenes. 


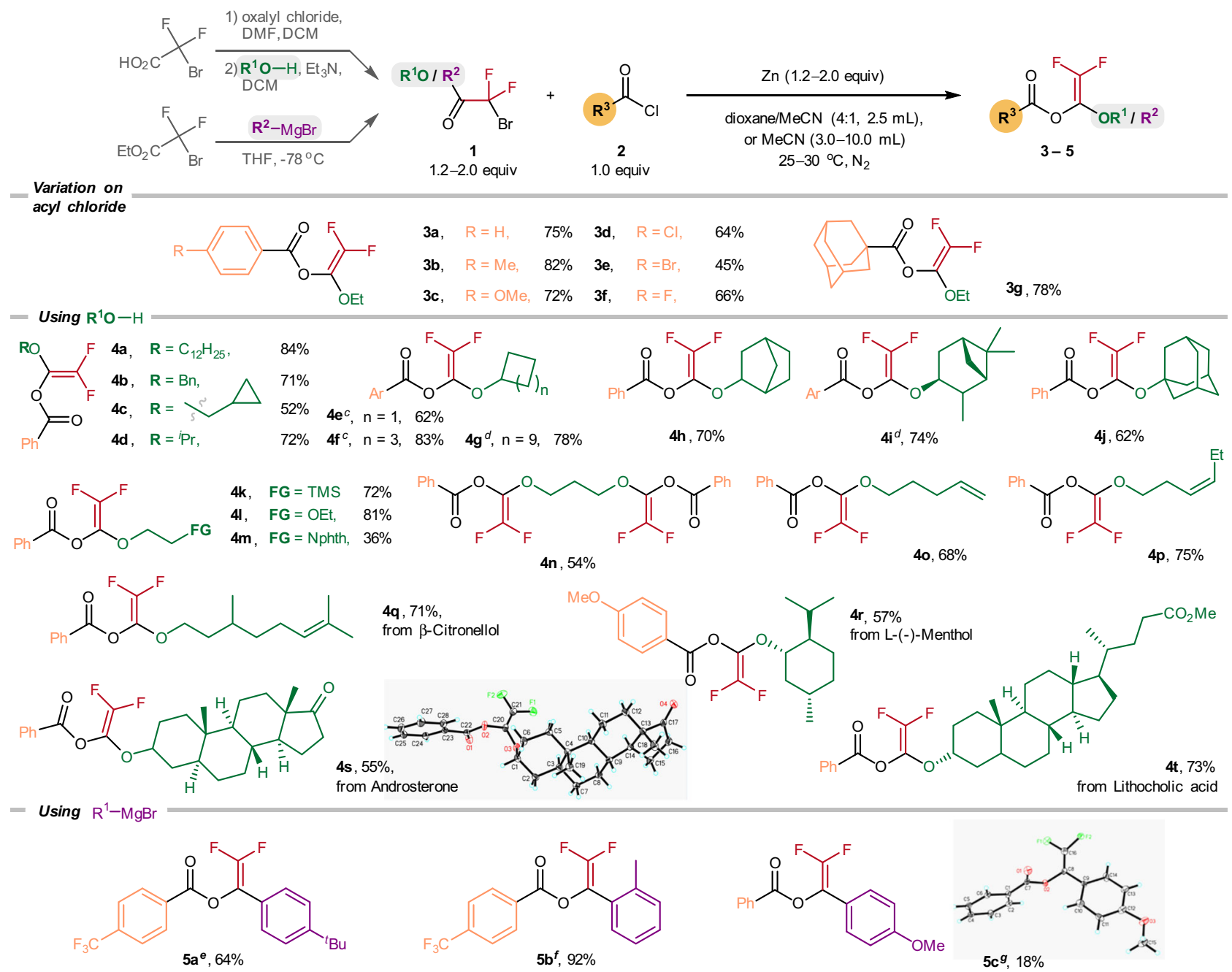

Fig. 2 Scope of 2,2-difluorovinyl benzoates (BzO-DFs) 2. aReaction conditions: 2-bromo-2,2-difluoroacetates (2.0 equiv), acyl chlorides (0.5 mmol), and $\mathrm{Zn}\left(2.0\right.$ equiv) in $2.5 \mathrm{~mL}$ dioxane/ $\mathrm{MeCN}(4: 1 \mathrm{v} / \mathrm{v})$ at $30{ }^{\circ} \mathrm{C}, 12 \mathrm{~h}, \mathrm{~N}_{2}$. blsolated yields. ${ }^{\mathrm{C}} \mathrm{Ar}=\mathrm{Ph} .{ }^{\mathrm{d}} \mathrm{Ar}=4-\mathrm{MeOC}_{6} \mathrm{H}_{4}$. ${ }^{\mathrm{e}} \mathbf{1 o}$ (3.0 equiv), 4-(trifluoromethyl) benzoyl chloride $(0.2 \mathrm{mmol}), \mathrm{Zn}$ (3.0 equiv) in $3.0 \mathrm{~mL} \mathrm{MeCN}$ at $25^{\circ} \mathrm{C}, 10 \mathrm{~h}, \mathrm{~N}_{2} .{ }^{\mathrm{f}} \mathbf{1 p}$ (1.5 equiv), 4-(trifluoromethyl)benzoyl chloride (0.2 mmol), Zn (2.0 equiv) in $3.0 \mathrm{~mL} \mathrm{MeCN}$ at $25^{\circ} \mathrm{C}, 10 \mathrm{~h}, \mathrm{~N}_{2} .{ }^{8} \mathbf{n n}$ (1.2 equiv), benzoyl chloride (2.0 mmol), and $\mathrm{Zn}$ (1.2 equiv) in $10.0 \mathrm{~mL} \mathrm{MeCN}$ at $25^{\circ} \mathrm{C}, 5 \mathrm{~h}, \mathrm{~N}_{2}$.

\section{Results}

Synthesis and scope of BzO-DFs. To begin, 2-bromo-2,2difluoroacetate $(1.0 \mathrm{mmol})$ was treated with benzoyl chloride $(0.5$ $\mathrm{mmol})$ and zinc powder (2.0 equiv) in a dioxane/MeCN $(4: 1 \mathrm{v} / \mathrm{v})$ mixture under a $\mathrm{N}_{2}$ atmosphere, and 3a was obtained in $77 \%$ yield (see Supplementary Information for optimization study). For structure characterization, the ${ }^{19} \mathrm{~F}$ NMR spectrum of $\mathbf{3 a}$ featured two characteristic doublet signals at -116 and -117 ppm, which is consistent with the gem-difluoroenol ether structure. The molecular structures of the $\mathrm{BzO}-\mathrm{DF}$ derivatives $4 s$ and $5 c$ have been unambiguously established by X-ray crystallography.

Employing the Zn-mediated protocol, we accomplished the synthesis of the $\mathrm{BzO}-\mathrm{DF}$ s involving diverse 2-bromo-2,2difluoroacetates and carboxylic acid chlorides (Fig. 2). Reacting 2-bromo-2,2-difluoroacetate with various substituted aroyl chlorides (4-Me, 4-OMe, 4- $\mathrm{Cl}, 4-\mathrm{Br}$, and 4-F) afforded the corresponding benzoates $(\mathbf{3 a}-\mathbf{3 f})$ in $45-82 \%$ yields. Coupling of the 1adamantanecarbonyl chloride with 2-bromo-2,2-difluoroacetate gave $3 \mathrm{~g}$ in $78 \%$ yield. The 2-bromo-2,2-difluoroacetates derived from simple primary alcohols such as $n$-dodecyl alcohol, benzyl alcohol, and cyclopropyl methanol were transformed to their difluorovinyl benzoates in $84 \%(4 \mathbf{a}), 71 \%(4 \mathbf{b})$, and $52 \%(4 \mathbf{c})$ yields, respectively.

Those 2-bromo-2,2-difluoroacetates derived from secondary and tertiary alcohols including isopropanol (4d: $72 \%)$, cyclobutanol (4e: 62\%), cyclohexanol (4f: 83\%), cyclododecanol (4g: 78\%), 2-exo-norbornanol (4h: 70\%), 3-pinanol (4i: 74\%), and 1adamantanol (4j: $62 \%$ ) were also effectively converted to their corresponding $\mathrm{BzO}-\mathrm{DF}$.

BzO-DFs containing a silyl (4k: 72\%), ether (4l: $81 \%$ ), phthalimide (4m: 36\%), and trimethylene glycol group (4n: $54 \%$ ) were also prepared, albeit in moderate yields. Similarly, those $\mathrm{BzO}-\mathrm{DF}$ analogs containing $\mathrm{C}=\mathrm{C}$ bonds $(4 \mathrm{o}$ : $68 \%$; $4 \mathrm{p}$ : $75 \%)$ were also obtained. Interestingly, $\mathrm{BzO}-\mathrm{DFs}$ derived from some bioactive natural products such as $\beta$-citronellol (4q: $71 \%$ ), androsterone (4s: 55\%), L-(-)-menthol (4r: 57\%) and lithocholic acid (4t: $73 \%)$ were also prepared successfully.

For the synthesis of the aryl-substituted $\mathrm{BzO}-\mathrm{DF}$ derivatives, we found that the best results were obtained by pairing electronpoor 4-(trifluoromethyl)benzoyl chloride with the bromodifluoroketones bearing electron-rich aryl substituents; the corresponding 5a (4-tert-butylaryl) and $\mathbf{5 b}$ (2-methylaryl) can be obtained in moderate to excellent yields $(64 \%, 92 \%)$. On a contrary, 
Table 1 Optimization of reaction conditions.

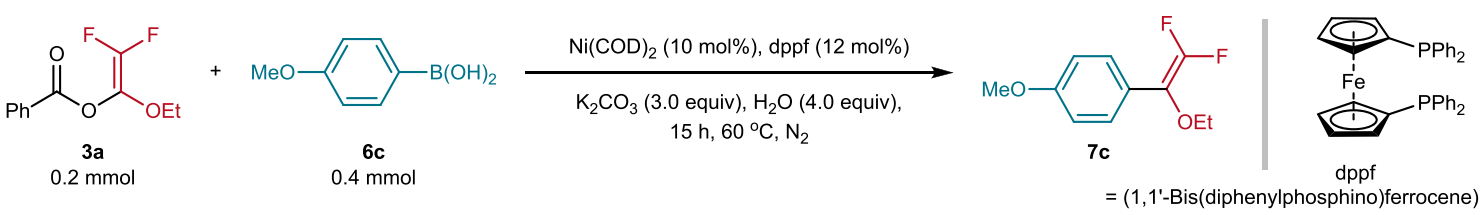<smiles>Pc1ccccc1-c1ccccc1</smiles>

dppbz
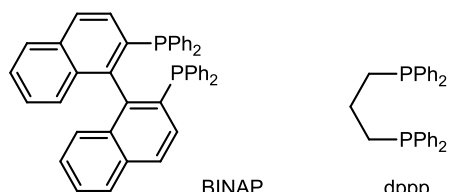

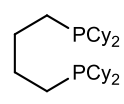

$\mathrm{dcpb}$

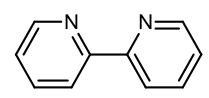

bpy

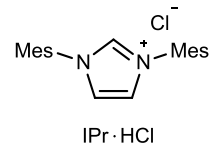

\begin{tabular}{lll}
\hline Entry & Deviation from standard conditions & Yield (\%) \\
\hline 1 & None & $87(84)^{\mathrm{b}}$ \\
2 & Ligand: $\mathrm{PPh}_{3} / \mathrm{dppbz} / \mathrm{dppp}$ instead of dppf & $<5$ \\
3 & Ligand: $\mathrm{dcpb}$ instead of dppf & 71 \\
4 & Ligand: $\mathrm{bpy} / \mathrm{Pr} \bullet \mathrm{HCl}$ instead of dppf & n.d.c \\
5 & Additives: $\mathrm{KOH} / \mathrm{KO} \mathrm{Bu}^{\mathrm{c}}$ instead of $\mathrm{K}_{2} \mathrm{CO}_{3}$ & n.d. \\
6 & Additives: $\mathrm{K}_{3} \mathrm{PO}_{4}$ instead of $\mathrm{K}_{2} \mathrm{CO}_{3}$ & 53 \\
7 & Additives: $\mathrm{Na}_{2} \mathrm{CO}_{3}$ instead of $\mathrm{K}_{2} \mathrm{CO}_{3}$ & 62 \\
8 & Additives: $\mathrm{K}_{2} \mathrm{CO}_{3}$ without $\mathrm{H}_{2} \mathrm{O}$ & 31 \\
9 & Additives: $\mathrm{K}_{2} \mathrm{CO}_{3}$ with $\mathrm{H}_{2} \mathrm{O}(8.0$ equiv) & 48 \\
10 & Solvent: $\mathrm{THF}$ instead of dioxane & 43 \\
11 & Solvent: $\mathrm{MeCN}$ instead of dioxane & $<5$ \\
12 & Solvent: $\mathrm{DMF}$ instead of dioxane & n.d. \\
13 & Solvent: ethyl acetate instead of dioxane & 36 \\
14 & Catalyst: $\mathrm{Ni}\left(\mathrm{PPh}_{3}\right)_{4}$ without ligand & \\
15 & Catalyst: $\mathrm{NiCl} l_{2} \mathrm{Ni}_{(\mathrm{OAc})_{2} \text { instead of } \mathrm{Ni}(\mathrm{COD})_{2}}$ & 40 \\
\end{tabular}

Reaction conditions: $3 \mathbf{a}(0.2 \mathrm{mmol}), \mathbf{6 c}\left(2.0\right.$ equiv) in solvent $(0.01 \mathrm{M})$, at $60^{\circ} \mathrm{C}, 15 \mathrm{~h}, \mathrm{~N}_{2}$.

aNMR yield determined by ${ }^{19} \mathrm{~F}$ NMR using trifluorotoluene as internal standard.

blsolated yield in parentheses.

c4-mhoxybenzophenone (7\%) was detected.

the analogous reaction of benzoyl chloride and the 4methoxyarylketone derivative afforded $5 \mathrm{c}$ in only $18 \%$ yield.

Reaction design and optimization. While the Ni-catalyzed $\mathrm{C}-\mathrm{O}$ bond activations $s^{42,43}$ of aryl carbonates ${ }^{44,45}$, aryl esters ${ }^{46,47}$, and aryl carbamates ${ }^{48,49}$ are well precedented, the analogous $\mathrm{C}-\mathrm{O}$ bond activation of vinyl benzoates is less established ${ }^{50}$. Our next goal is to examine the $\mathrm{Ni}$-catalyzed coupling reaction of $\mathrm{BzO}-\mathrm{DFs}$ with arylboronic acids as nucleophiles through regioselective $\mathrm{C}$ (vinyl)-O(benzoate) bond activation. Pleasingly, when 3a was treated with 4-methoxyphenylboronic acid $\mathbf{6 c}$ in the presence of $\mathrm{Ni}(\mathrm{COD})_{2} \quad(\mathrm{COD}=$ cyclooctadiene; $10 \mathrm{~mol} \%)$, dppf $\left(1,1^{\prime}\right.$-bis (diphenylphosphino)ferrocene; $12 \mathrm{~mol} \%$ ), $\mathrm{K}_{2} \mathrm{CO}_{3}$ (3.0 equiv), and water (4.0 equiv) in dioxane $(0.01 \mathrm{M})$ under an $\mathrm{N}_{2}$ atmosphere, the desired gem-difluoroenol ether $7 \mathrm{c}$ was obtained in $87 \%$ yield (Table 1 , entry 1 ).

As shown in Table 1, the result with dppf as ligand is outstanding when compared to other common auxiliary ligands (Table 1, entry 2). Notably, the use of dcpb [1,4-bis(dicyclohexylphosphino)butane] furnished $7 \mathrm{c}$ in $71 \%$ yield (Table 1 , entry 3 ); yet bpy (2,2'-bipyridyl) and IPr.HCl (1,3-dimesityl-1H-imidazol3 -ium chloride) known to be utilized for some Ni-catalyzed cross couplings are completely ineffective (Table 1, entry 4).

The choice of bases was also critical; the use of strong bases such as $\mathrm{KOH}$ or $\mathrm{KO}^{t} \mathrm{Bu}$ led to decomposition of $\mathbf{3 a}$ without $7 \mathbf{c}$ being detected (Table 1, entry 5). Employing $\mathrm{K}_{3} \mathrm{PO}_{4}$ and $\mathrm{Na}_{2} \mathrm{CO}_{3}$ as bases gave $7 \mathrm{c}$ in $53 \%$ and $62 \%$, respectively (Table 1 , entries 6-7). Apparently, 4.0 equiv of water as additive produced the best result. Reaction run under anhydrous conditions afforded $7 \mathrm{c}$ in only $31 \%$ yield (Table 1 , entry 8 ); see Supplementary Information for details. The coupling was also sensitive to the reaction medium. When THF was used in lieu of dioxane, the yield of 7c decreased significantly to $43 \%$ (Table 1 , entry 10); the coupling reaction was largely suppressed when polar aprotic solvents such as MeCN, DMF and ethyl acetate were employed (Table 1, entries 11-13). Although $\mathrm{Ni}\left(\mathrm{PPh}_{3}\right)_{4}$ was catalytically active for this transformation with $7 \mathrm{c}$ being formed in $40 \%$ yield (Table 1, entry 14); $\mathrm{Ni}(\mathrm{II})$ salts such as $\mathrm{NiCl}_{2}$ and $\mathrm{Ni}(\mathrm{OAc})_{2}$ were completely inactive with complete recovery of the starting materials (Table 1 , entry 15).

Substrate scope. With the optimized conditions, we performed the cross-coupling scope study with a series of arylboronic acids (Fig. 3). For para-substituted arylboronic acids except those containing SMe (7g, 30\%), OH (7h, 34\%), and $\mathrm{Cl}(\mathbf{7 j}, 42 \%)$, the $\mathrm{Ni}$-catalyzed coupling products were furnished in synthetically meaningful yields (7a-7f, 7i). Arylboronic acids with coordinating nitrogen-, oxygen- and $\mathrm{C}=\mathrm{C}$ moieties also reacted smoothly (7k: 52\%; 7l: 50\%, 7m: 40\%). Similarly, successful couplings were also accomplished for the arylboronic acids with naphthalene motifs (7n: 76\%; 7o: 82\%), disubstituted aryl groups (7p: 78\%), and polyheterocyclic functions $(7 \mathbf{q}: 74 \% ; 7 \mathbf{r}: 74 \% ; 7 \mathrm{~s}: 56 \% ; 7 \mathrm{t}$ : $51 \%)$. Moreover, the coupling reactions have been applied for late-stage modification of some natural products compounds. For examples, the coupling reactions with the arylboronic acids derived from vitamin $\mathrm{E}$, estrone and flavanone afforded the desired coupled products in moderate yields $(7 \mathbf{u}: 26 \% ; 7 \mathbf{v}: 60 \%$; 7w: 39\%).

Under the Ni-catalyzed conditions, $\mathrm{BzO}-\mathrm{DF}$ derived from simple primary alcohols (8a-8c: $66-89 \%)$ and several secondary 


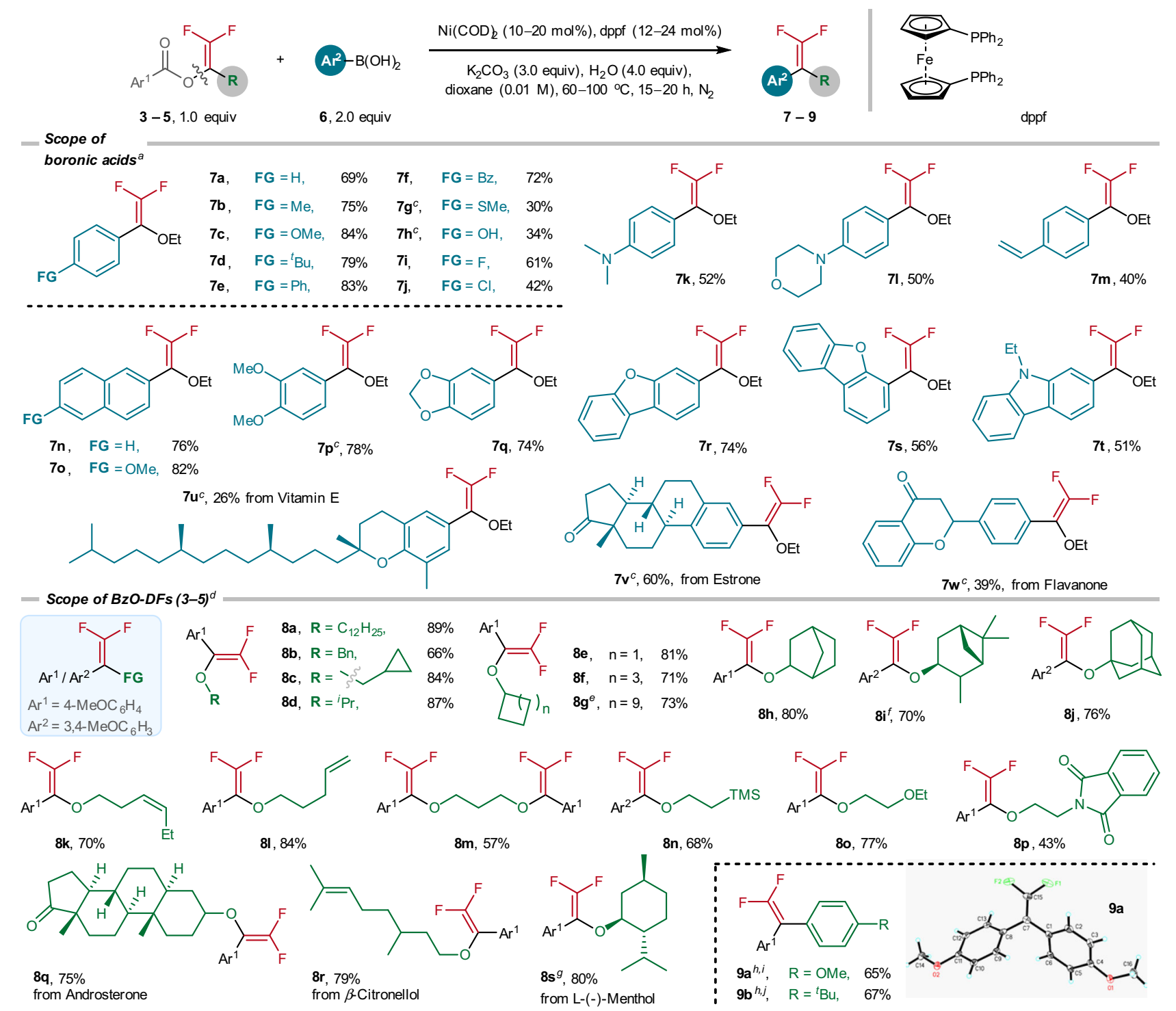

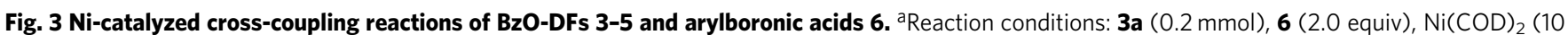
mol\%), dppf (12 mol\%), $\mathrm{H}_{2} \mathrm{O}$ (4.0 equiv), $\mathrm{K}_{2} \mathrm{CO}_{3}$ (3.0 equiv) in dioxane (0.01 M) at $80^{\circ} \mathrm{C}, 20 \mathrm{~h}, \mathrm{~N}_{2}$. blsolated yields. ${ }^{\mathrm{C}} \mathrm{Ni}(\mathrm{COD}) 2(20 \mathrm{~mol} \%), \mathrm{dppf}(24 \mathrm{~mol}$ $\%), 80^{\circ} \mathrm{C}, 20 \mathrm{~h}$. dReactions were performed at $60^{\circ} \mathrm{C}$ for $15 \mathrm{~h}$. eUsing $\mathbf{4} \mathbf{g}$ instead of $\mathbf{3 a}$. ${ }^{\mathrm{f}}$ Using $\mathbf{4 i}$ instead of 3a. gUsing $\mathbf{4 r}$ instead of $\mathbf{3 a}$. ${ }^{\mathrm{h}} \mathrm{Ni}(\mathrm{COD})_{2}(20 \mathrm{~mol}$ $\%), \operatorname{dppf}(24 \mathrm{~mol} \%), 100{ }^{\circ} \mathrm{C}, 20 \mathrm{~h}$. 'Using $\mathbf{5 c}$ instead of $\mathbf{3 a}$. Jusing $\mathbf{5 a}$ instead of $\mathbf{3 a}$.

and cycloalkanols (8d: $87 \%, \mathbf{8 e - 8 g : ~} 71-83 \%)$ were readily transformed to the corresponding coupled products. Gratifyingly, the benzoates with 2-exo-norbornanyl (8h: 80\%), pinanyl (8i: 70\%), and adamantyl (8j: 76\%) were effectively arylated. Successful coupling reactions were achieved with benzoates derived from difunctionalized alcohols such as alkene $(\mathbf{8 k}: 70 \%$, 81: 84\%), 1,3-propandiol (8m: 57\%), trimethylsilyl ethanol (8n: 68\%), ethereal (8o: $77 \%)$, and phthalimide moieties (8p: $43 \%)$ were well tolerated. The coupling reactions of 4methoxyphenylboronic acid with the benzoates derived from androsterone (8q: 75\%), $\beta$-citronellol (8r: 79\%), and L(-)-menthol (8s: $80 \%)$ were also successfully accomplished. In this work, two BzO-DFs derived from bromodifluoroketones (1v, $\mathbf{1 x})$ were also transformed to corresponding gem-difluoroalkenes (9a: 65\%, 9b: 67\%). The molecular structure of 9a has been established by X-ray crystallography.

Synthetic applications. We are gratified that the difluorovinyl benzoates synthesis and the subsequent $\mathrm{Ni}$-catalyzed cross- coupling reactions can be performed in a larger scale (2.0-6.0 mmol) without significant drop in yields (Fig. $4 \mathrm{a})$. The practicability of $\mathrm{BzO}-\mathrm{DF}$ as the building blocks is also demonstrated by their favorable reactivity towards a wide range of coupling partners (Fig. 4b). Apart from arylboronic acids, aryl Grignard reagent was also found to be effective coupling partner. Employing $\mathrm{Ni}(\mathrm{COD})_{2}(10 \mathrm{~mol} \%)$ as catalyst and $\mathrm{PPh}_{3}(20 \mathrm{~mol} \%)$, 3a reacted (4-methoxyphenyl)magnesium bromide to furnish 7c in $45 \%$ yield (Fig. 4 b, eq. 1 ). The current Ni-catalyzed reaction can be extended to $\mathrm{C}\left(\mathrm{sp}^{2}\right)-\mathrm{C}\left(\mathrm{sp}^{3}\right)$ bond construction using some common alkyl-metal nucleophiles. For instance, the less-reactive $n$-hexylzinc bromide (Fig. 4b, eq. 2) and benzylzinc bromide (Fig. 4b, eq. 3) [dppf ( $24 \mathrm{~mol} \%)$ as ligand)] with $\mathbf{4 b / 3 a}$ gave the corresponding difluoroalkenes 11 and $\mathbf{1 0}$ in $38 \%$ and $22 \%$ yields, respectively.

In this work, we also examined the possibility to engage 3 a with some electrophiles for cross electrophile coupling reactions. We are pleased that benzyl chloride successfully coupled 3a to give $\mathbf{1 0}$ in $47 \%$ yield using some conventional $\mathrm{Ni}$-catalyzed reductive coupling conditions: $\mathrm{Ni}(\mathrm{OAc})_{2}(10 \mathrm{~mol} \%)$, bpy $(12 \mathrm{~mol} \%)$ and 
a)

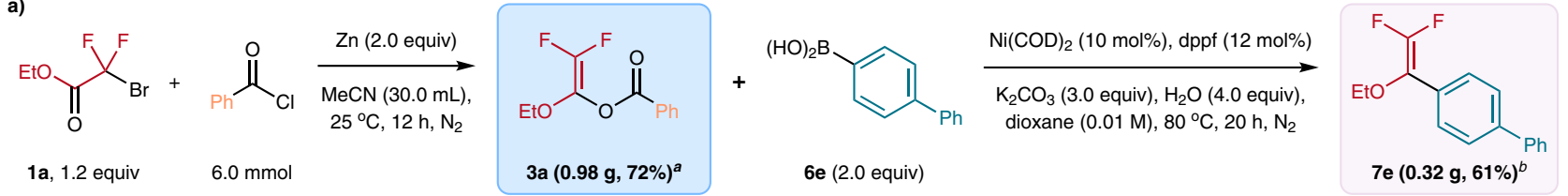

b)

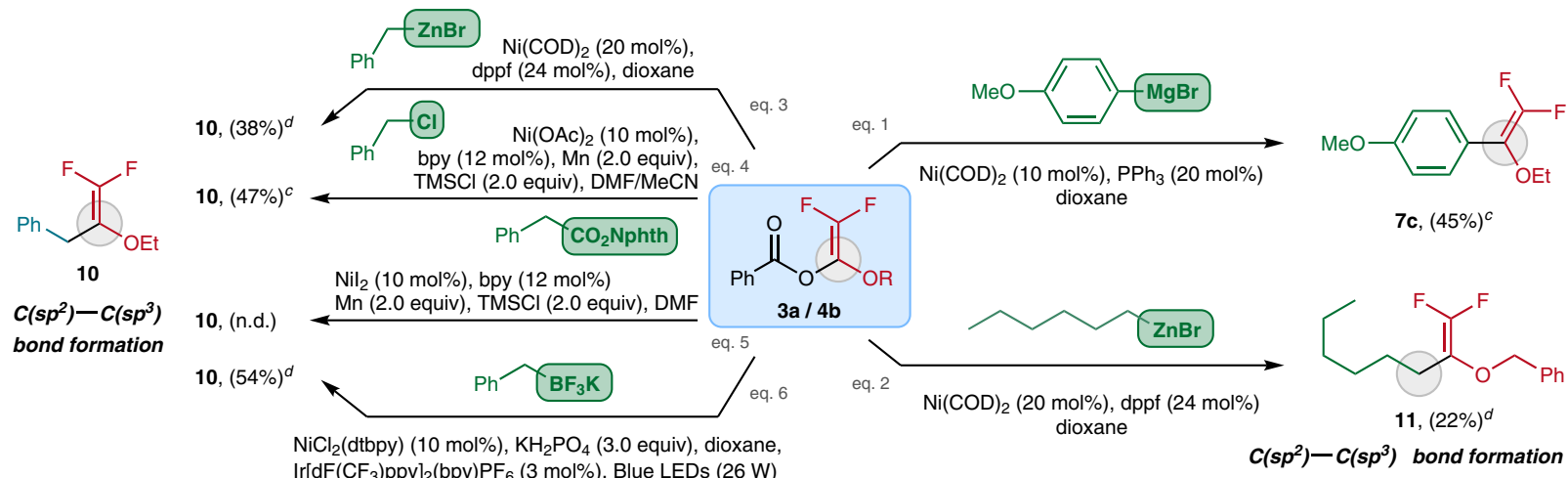

Fig. 4 Synthetic applications. a Gram-scale operation of the BzO-DFs synthesis and the subsequent Ni-catalyzed arylation. $\mathbf{b}$ Exploration of the coupling partners with the BzO-DF building blocks: catalytic protocols based on the uses of organometallic nucleophiles such as organomagnesium/-zinc and organotrifluoroborates as well as electrophiles such as benzyl chlorides have been developed. ${ }^{\mathbf{a}} \mathbf{1} \mathbf{a}(1.46 \mathrm{~g})$ was used at starting material. ${ }^{\mathrm{3}} \mathbf{3} \mathbf{a}$ ( $0.46 \mathrm{~g}$ ) was used for the Ni-catalyzed coupling reaction. ${ }^{C N M R}$ yield determined by ${ }^{19} \mathrm{~F}$ NMR with trifluorotoluene as internal standard. ${ }^{\mathrm{d}}$ solated yields.

Mn (2.0 equiv) (Fig. 4b, eq. 4). Redox-active ester failed to alkylate with 3a under similar reductive coupling conditions (Fig. 4c, eq. 5). Apparently, our " $\mathrm{Ni}(\mathrm{COD})_{2}+$ dppf" protocol is not effective when potassium benzyltrifluoroborate was employed as the coupling partner. Yet, effective $\mathrm{C}\left(\mathrm{sp}^{2}\right)-\mathrm{C}\left(\mathrm{sp}^{3}\right)$ coupling was achieved under photochemical conditions. When we employed Molander's protocol [i.e., $\mathrm{NiCl}_{2}$ (dtbpy) (10 mol\%), $\operatorname{Ir}\left[\mathrm{dF}\left(\mathrm{CF}_{3}\right)\right.$ ppy $]_{2}$ (bpy) $\mathrm{PF}_{6}$ (3 mol\%), blue light $\left.(26 \mathrm{~W})\right]$, benzyltrifluoroborate reacted with 3a to forge $\mathbf{1 0}$ formation in 54\% yield (Fig. 4b, eq.6).

Mechanistic studies. Underlying the favorable reactivity of the $\mathrm{BzO}-\mathrm{DFs}$ for gem-difluoroenol ethers synthesis is the regioselective $\mathrm{C}$ (vinyl)-O(benzoate) bond activation. Compared to the $\mathrm{C}$ (acyl)/C(alkyl)-O bonds activation, the observed selectivity may be attributed to the better leaving group reactivity of the benzoates ${ }^{47}$. In this regard, we performed a correlation study using a series of BzO-DFs $(\mathbf{3 a} / \mathbf{3 b} \mathbf{3} \mathbf{3} \mathbf{c} / \mathbf{3 d} \mathbf{\mathbf { d }} \mathbf{3} \mathbf{f} / \mathbf{3 h} / \mathbf{3 i})$, which bear a series of substituted benzoic acids as leaving groups. Four sets of competition reaction: $[\mathbf{3} \mathbf{a}+\mathbf{3 b}],[\mathbf{3} \mathbf{a}+\mathbf{3} \mathbf{c}],[\mathbf{3} \mathbf{a}+\mathbf{3} \mathbf{d}],[\mathbf{3} \mathbf{a}+\mathbf{3} \mathbf{f}],[\mathbf{3} \mathbf{a}+\mathbf{3} \mathbf{h}]$, $[\mathbf{3} \mathbf{a}+\mathbf{3 i}]$ were performed, and the yields of remaining substrates were determined by ${ }^{19} \mathrm{~F}$ NMR with $\mathrm{PhCF}_{3}$ as an internal standard. Plotting $\log \left(k_{\mathrm{FG}} / k_{\mathrm{H}}\right)$ with the Hammett $\sigma$ (para) constants resulted a linear plot with a slope of $+0.82\left(R^{2}=0.82\right)$ of $\log \left(\mathrm{k}_{\mathrm{FG}} /\right.$ $\mathrm{k}_{\mathrm{H}}$ ) against the $\sigma$ (para) constants. This finding indicated a faster reaction rate is promoted by electron-withdrawing substituents on the benzoates. This implies that partial negative charge buildup at the transition state of the oxidative addition.

In terms of product formation, it was found that the $\mathrm{Ni}$ catalyzed arylation of $\mathbf{3 a}-\mathbf{3 f}$ exhibited rather optimal yields $(>80 \%)$ when the $\mathrm{pKa}$ values are within the range of 4.14-4.57. Lower yields were observed for $\mathbf{3 d}$ ( $\mathrm{LG}=4$-chlorobenzoic acid) and $3 \mathbf{e}(\mathrm{LG}=4$-bromobenzoic acid) despite of the lower $\mathrm{pKa}$ values of 3.97. (Fig. 5b). As expected, for the $\mathrm{BzO}-\mathrm{DF}$ with adamantanecarboxylic acid ( $\mathrm{pKa}=4.86$ ) as the leaving group, no coupling product was obtained under the standard conditions (see Supplementary Information for details). The benzoates were indeed the leaving group for the $\mathrm{C}($ vinyl)-O activation; this is verified by the isolation of the benzoic acids in $76 \%$ yield after treating the reaction crude with $\mathrm{HCl}$ (aq) (Fig. 5c, eq. 1).
Regarding to the mechanism, $\mathrm{Ni}(0)$ complexes are known to effect $\mathrm{C}\left(\mathrm{sp}^{2}\right)$-halide bond activation initiated by single-electron transfer mechanism. It appeared plausible that the $\mathrm{C}$ (vinyl)-O (benzoate) activation may proceed via initial single-electron reduction of the $\mathrm{BzO}-\mathrm{DFs}$ by the $\mathrm{Ni}(0)$ complex, leading to carboradicals formation via the $\mathrm{C}-\mathrm{O}$ bond fragmentation. In this work, the radical mechanism was scrutinized by using TEMPO as radical trap. When the " $\mathbf{3 a}+\mathbf{6} \mathbf{c}$ " reaction was performed in the presence of TEMPO (2.0 equiv), the $7 \mathrm{c}$ formation was completed suppressed with $61 \%$ recovery of the starting 3a (Fig. 5c, eq. 2). Apparently, no TEMPO-radical adducts were detected by GC-MS and LC-HRMS analysis of the reaction mixture. The lack of product formation could be attributed to the oxidation of the active $\mathrm{Ni}(0)$ complexes by the TEMPO, resulting in the loss of the catalytic activity. Consistent with this notion, when BHT (2.0 equiv) was used in place of TEMPO as radical trap, effective formation of $7 \mathrm{c}(85 \%)$ was detected by NMR analysis (Fig. 5b, eq. 3). Furthermore, when $\mathbf{3 a}$ and $\mathbf{6 c}$ were subjected to the $\mathrm{Ni}$ catalyzed conditions in the presence of $\alpha$-cyclopropylstyrene (2.0 equiv) as radical probe, $7 c$ was formed in $75 \%$ yield and the radical probe was completely recovered unchanged (Fig. $5 c$, eq. 4). On the basis of these findings, pathways involving radical formation is untenable.

We performed density-functional theory (DFT) calculation to delineate the mechanistic details of the reaction. We chose the " $\mathbf{3 a}$ $+6 c^{\prime}$ reaction as a model for our DFT study. Based on our ligand screening study, we believed that the dppf-ligated $\mathrm{Ni}(0)$ species $\mathbf{A}$ is the active species to initiate the coupling reaction. Oxidative addition of 3a should pass through a barrier of $\sim 27.2 \mathrm{kcal} \mathrm{mol}^{-1}$. This step is found to be the rate-determining step ${ }^{51,52}$. As shown in Fig. 6, oxidative addition of $\mathbf{3 a}$ to form complex $\mathbf{B}$ is nearly a thermal neutral process. Yet, the major driving force of the oxidative addition appears to be the ligand exchange reaction of the benzoate with $\mathrm{K}_{2} \mathrm{CO}_{3}$ to form complex $\mathrm{C}$, which is highly exergonic with a drop of the relative Gibbs free energy from 2.0 $\mathrm{kcal} \mathrm{mol}^{-1}$ to $-12.4 \mathrm{kcal} \mathrm{mol}^{-1}$. Subsequent transmetalation with arylboronic acid $\mathbf{6 c}$ takes place via a six-membered ring transition state $\left(\mathbf{T S}_{\mathbf{C - D}}\right)$ to generate intermediate $\mathbf{D}^{53,54}$. The transmetalation is followed by spontaneous reductive elimination to give $\mathrm{Ni}$ 


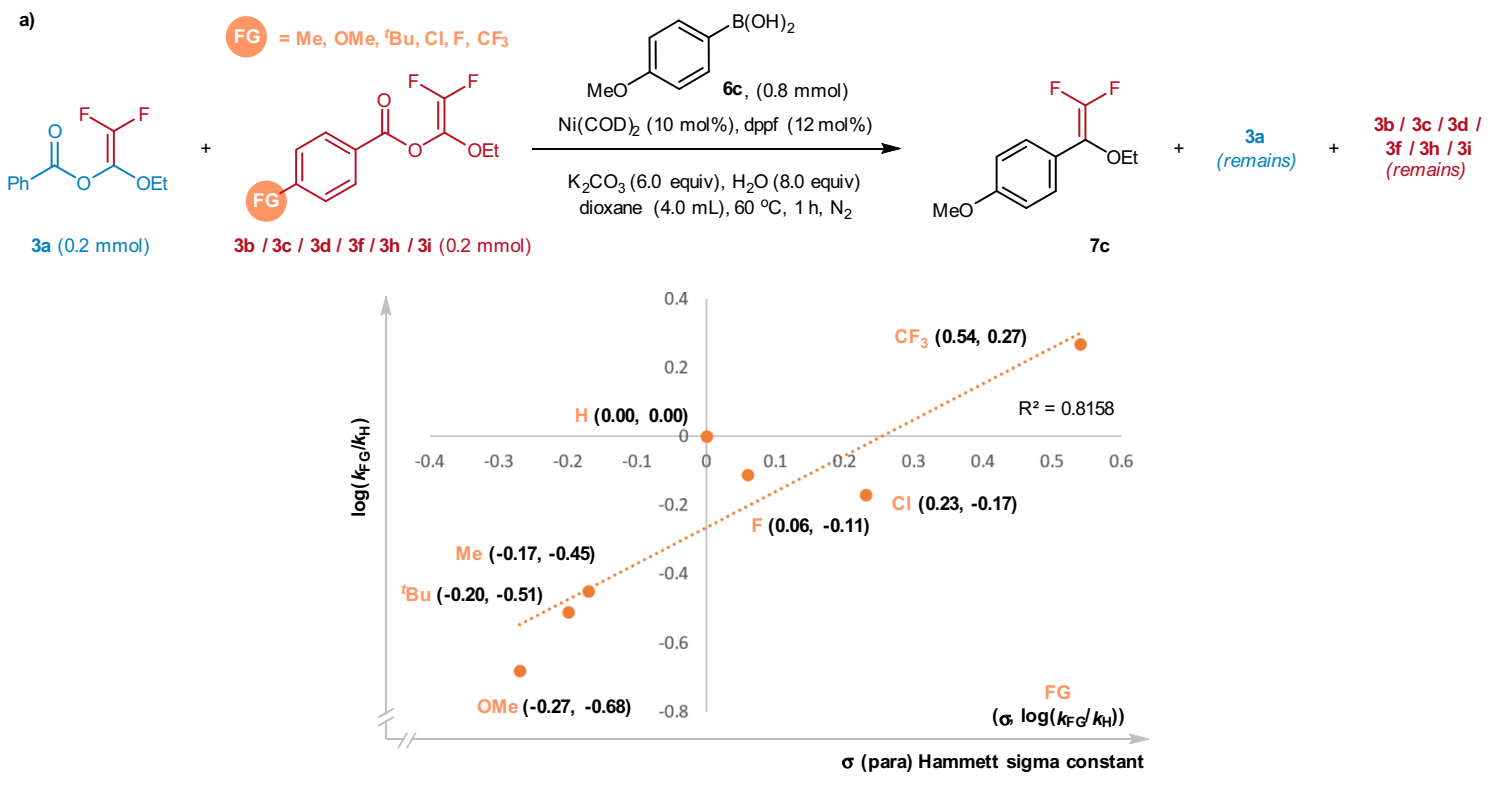

b)
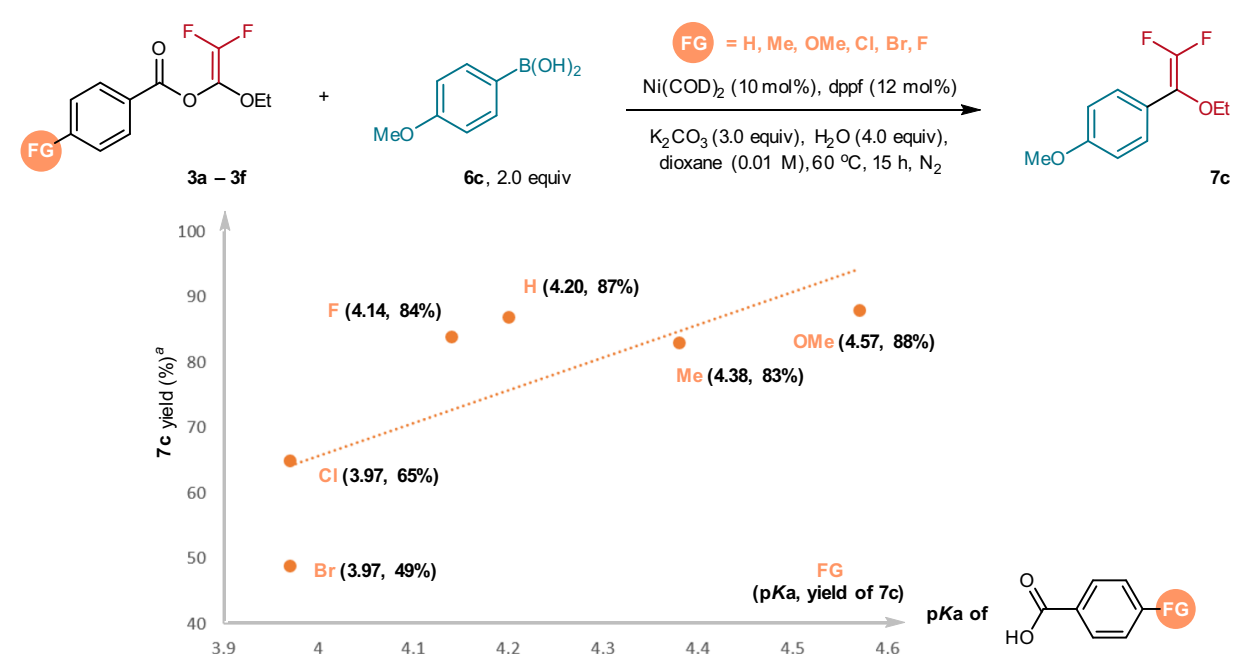

c)

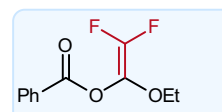

3a

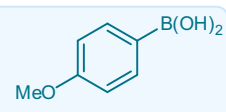

6c, 2.0 equiv

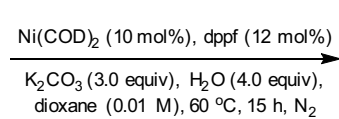
dioxane $(0.01 \mathrm{M}), 60^{\circ} \mathrm{C}, 15 \mathrm{~h}, \mathrm{~N}_{2}$

= Standard conditions
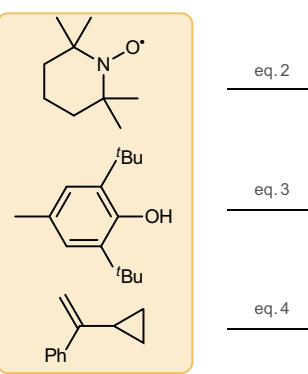
$7 c$

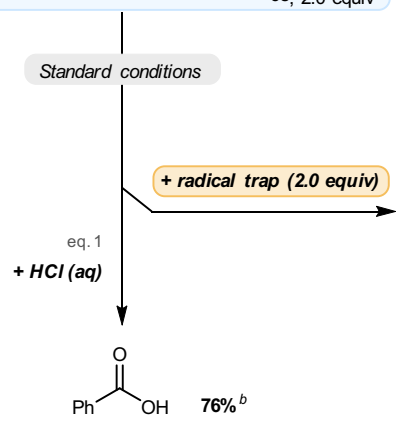<smiles>CCOC(=C(F)F)c1ccc(OC)cc1</smiles>

7c, n.d $+\quad 3 a, 61 \%^{b}$
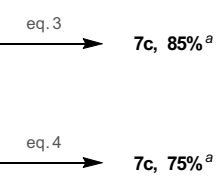

Fig. 5 Mechanistic studies. a Hammett correlation study of the Ni-catalyzed cross-coupling reactions of BzO-DFs 3 and arylboronic acids $6 \mathbf{a}$. $\mathbf{b}$ Effects of

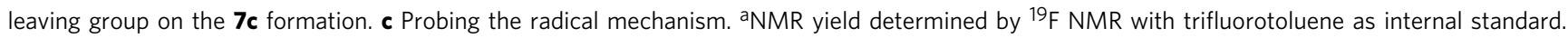
blsolated yields. 


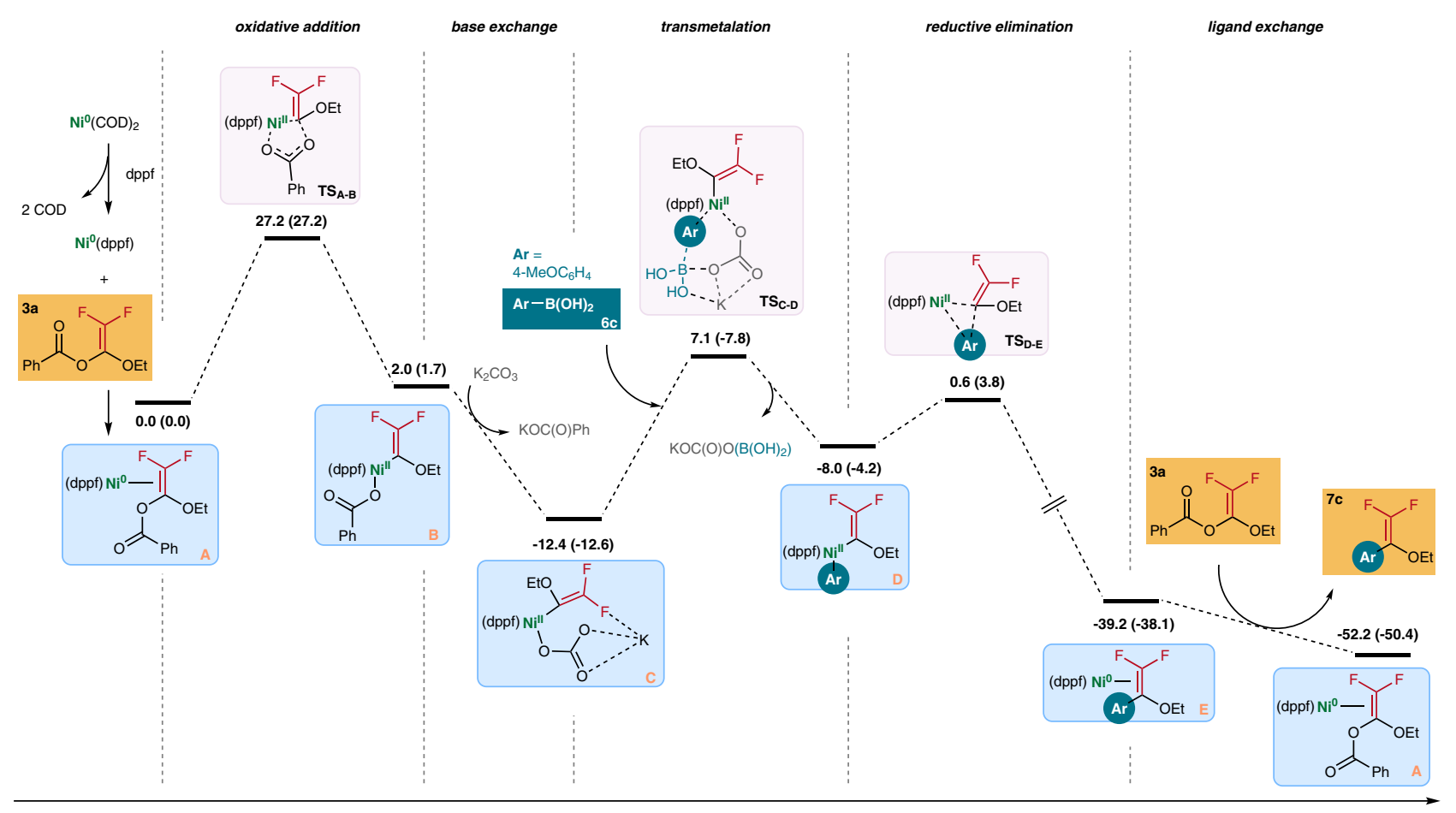

Fig. 6 Gibbs free energy profile calculated for the Ni-catalyzed reaction of $\mathbf{3 a}$ and $\mathbf{6 c}$. The relative Gibbs energies and Electronic energies (in parentheses) are given in $\mathrm{kcal} / \mathrm{mol}$.

(0) complex $\mathbf{E}$ involving a drop of $\Delta \mathrm{G}$ of the system from -8.0 $\mathrm{kcal} \mathrm{mol}^{-1}$ to $-39.2 \mathrm{kcal} \mathrm{mol}^{-1}$. Finally, E reacts with $\mathbf{3 a}$ through ligand exchange to give product $7 \mathrm{c}$ with the regeneration of the active species $\mathbf{A}$, which is very facile with low energy barriers.

In summary, we developed a modular synthesis of gemdifluoroenol ethers and gem-difluoroalkenes by the Ni-catalyzed coupling with structurally diverse $\mathrm{BzO}-\mathrm{DF}$. The $\mathrm{BzO}-\mathrm{DF}$ s can be easily prepared from abundant bromodifluoroketones and bromodifluoroacetates. Exhibiting remarkable functional groups tolerance, this $\mathrm{Ni}$-catalyzed protocol permits easy installation of a gem-difuorovinyl group to bioactive molecules. This reaction should supplement the conventional strategies in exploiting difluorovinyl moieties in drug design and development. Control experiments and DFT calculations revealed that the reaction is initiated by regioselective oxidative addition of the $\mathrm{BzO}-\mathrm{DFs}$ by the $\mathrm{Ni}(0)$ complex. The intermediate vinylnickel(II) benzoate complexes readily exchanged with organometallic nucleophiles enabling a versatile $\mathrm{C}\left(\mathrm{sp}^{2}\right)-\mathrm{C}\left(\mathrm{sp}^{2}\right)$ and $\mathrm{C}\left(\mathrm{sp}^{2}\right)-\mathrm{C}\left(\mathrm{sp}^{3}\right)$ coupling manifolds.

\section{Methods}

General procedure for preparation of BzO-DFs (3-5). To a $25 \mathrm{~mL}$ roundbottom flask with a magnetic stir bar was added acyl chloride (1.0 equiv, $0.5 \mathrm{mmol}$ ), $\mathrm{Zn}$ powder (2.0 equiv, $1.0 \mathrm{mmol}), \mathrm{MeCN}(0.5 \mathrm{~mL})$ and dioxane $(1.5 \mathrm{~mL})$ in a nitrogen-filled glovebox. The reaction mixture was then sealed with a rubber septum and removed from the glovebox. To the mixture, 1 (2.0 equiv, $1.0 \mathrm{mmol})$ was diluted with dioxane $(0.5 \mathrm{~mL})$ and added with a syringe pump over $20 \mathrm{~min}$. After stirring the reaction mixture for further $12 \mathrm{~h}$ at $30^{\circ} \mathrm{C}$, the reaction mixture was filtered, and the filtrate was concentrated in vacuo. The residue was purified by flash column chromatography ( $n$-hexane:ethyl acetate $=200: 1-50: 1)$ to give the desired 2,2-difluorovinyl benzoates.

General Procedure for Ni-catalyzed cross-coupling reaction between BzO-DFs (3-5) and arylboronic acids. To a $8 \mathrm{~mL}$ vial equipped with a magnetic stir bar was added 2,2-difluorovinyl benzoate 3-5 (1.0 equiv, $0.2 \mathrm{mmol}$ ), arylboronic acid $\mathbf{6}(2.0$ equiv, $0.4 \mathrm{mmol}$ ), $\mathrm{K}_{2} \mathrm{CO}_{3}$ (3.0 equiv, $0.6 \mathrm{mmol}$ ) and deionized water (4.0 equiv, 0.8 $\mathrm{mmol})$ in a nitrogen-filled glovebox. Then a premixed solution of $\mathrm{Ni}(\mathrm{COD})_{2}(10 \mathrm{~mol}$ $\%, 0.02 \mathrm{mmol})$, dppf ( $12 \mathrm{~mol} \%, 0.024 \mathrm{mmol})$ and dioxane $(0.01 \mathrm{M}, 2.0 \mathrm{~mL})$ was transferred to the reaction mixture. The $8 \mathrm{~mL}$ vial was then capped and removed from the glovebox. After stirring the reaction mixture for $15 \mathrm{~h}$ at $60^{\circ} \mathrm{C}$, the reaction mixture was cooled to room temperature and diluted with ethyl acetate. The solution was then filtered through a pad of Celite ${ }^{\circledR}$. The filtrate was then dried over $\mathrm{MgSO}_{4}$ and concentrated in vacuo. The residue was purified by flash column chromatography $(n-$ hexane:ethyl acetate $=200: 1-50: 1)$ to give the desired products.

\section{Data availability}

All data are available from the corresponding authors upon reasonable request. The $\mathrm{X}$ ray crystallographic coordinates for structures reported in this study have been deposited at the Cambridge Crystallographic Data Centre (CCDC), under deposition numbers $2008864(\mathbf{4 s}), 1921828$ (5c), and $1921829(\mathbf{9 a})$. These data can be obtained free of charge from The Cambridge Crystallographic Data Cenrte via www.ccdc.cam.ac.uk/ data_request/cif”.

Received: 24 February 2020; Accepted: 10 December 2020; Published online: 18 January 2021

\section{References}

1. Meanwell, N. A. Synopsis of some recent tactical application of bioisosteres in drug design. J. Med. Chem. 54, 2529-2591 (2011).

2. Bégué, J. P. \& Bonnet-Delpon, D. Antimalarial Fluoroartemisinins: Increased Metabolic and Chemical Stability. In Fluorine in Medicinal Chemistry and Chemical Biology, Ojima, I., Ed. pp 141-163 (Blackwell Publishing Ltd, 2009).

3. Malátková, P. \& Wsól, V. Carbonyl reduction pathways in drug metabolism. Drug Metab. Rev. 46, 96-123 (2014).

4. Barski, O. A., Tipparaju, S. M. \& Bhatnagar, A. The aldo-keto reductase superfamily and its role in drug metabolism and detoxification. Drug Metab. Rev. 40, 553-624 (2008)

5. Magueur, G., Crousse, B., Ourévitch, M., Bonnet-Delpon, D. \& Bégué, J.-P. Fluoro-artemisinins: when a gem-difluoroethylene replaces a carbonyl group. J. Fluor. Chem. 127, 637-642 (2006).

6. Fujita, T., Fuchibe, K. \& Ichikawa, J. Transition-metal-mediated and -catalyzed $\mathrm{C}-\mathrm{F}$ bond activation by fluorine elimination. Angew. Chem. Int. Ed. 58, 390-402 (2019).

7. Zhang, X. \& Cao, S. Recent advances in the synthesis and C-F functionalization of gem-difluoroalkenes. Tetrahedron Lett. 58, 375-392 (2017).

8. Yoo, W.-J., Kondo, J., Rodríguez-Santamaría, J. A., Nguyen, T. V. Q. \& Kobayashi, S. Efficient synthesis of $\alpha$-trifluoromethyl carboxylic acids and esters through fluorocarboxylation of gem-difluoroalkenes. Angew. Chem. Int. Ed. 58, 6772-6775 (2019). 
9. Liu, H., Ge, L., Wang, D.-X., Chen, N. \& Feng, C. Photoredox-coupled Fnucleophilic addition: allylation of gem-difluoroalkenes. Angew. Chem. Int. Ed. 58, 3918-3922 (2019).

10. Nguyen, B. V. \& Burton, D. J. A new route for the preparation of substituted 2,2-difluorostyrenes and a convenient route to substituted $(2,2,2$ Trifluoroethyl)benzenes. J. Org. Chem. 62, 7758-7764 (1997).

11. Huang, X. et al. The ortho-difluoroalkylation of aryliodanes with enol silyl ethers: rearrangement enabled by a fluorine effect. Angew. Chem. Int. Ed. 58, 5956-5961 (2019).

12. Liu, J., Yang, J., Ferretti, F., Jackstell, R. \& Beller, M. Pd-catalyzed selective carbonylation of gem-difluoroalkenes: a practical synthesis of difluoromethylated esters. Angew. Chem. Int. Ed. 58, 4690-4694 (2019).

13. Motherwell, W. B., Tozer, M. J. \& Ross, B. C. A convenient method for replacement of the anomeric hydroxy group in carbohydrates by difluoromethyl functionality. J. Chem. Soc. Chem. Commun. 1437-1439 (1989).

14. Kodama, Y., Yamane, H., Okumura, M., Shiro, M. \& Taguchi, T. Lewis acid catalyzed aldol-type reaction of 1,1-difluorovinyl methyl ether derivatives. Tetrahedron 51, 12217-12228 (1995)

15. Hu, J., Han, X., Yuan, Y. \& Shi, Z. Stereoselective synthesis of $\mathrm{z}$ fluoroalkenes through copper-catalyzed hydrodefluorination of gem-difluoroalkenes with water. Angew. Chem. Int. Ed. 56, 13342-13346 (2017).

16. Sakaguchi, H. et al. Copper-catalyzed regioselective monodefluoroborylation of polyfluoroalkenes en route to diverse fluoroalkenes. J. Am. Chem. Soc. 139, 12855-12862 (2017).

17. Tian, P., Feng, C. \& Loh, T.-P. Rhodium-catalysed C(sp2)-C(sp2) bond formation via C-H/C-F activation. Nat. Commun. 6, 1-7 (2015).

18. Lu, X. et al. Nickel-catalyzed defluorinative reductive cross-coupling of gemdifluoroalkenes with unactivated secondary and tertiary alkyl halides. J. Am. Chem. Soc. 139, 12632-12637 (2017).

19. Fuchibe, K., Ueda, M., Yokota, M. \& Ichikawa, J. $\gamma$-selective addition to 1,1 difluoroallenes: three-component coupling leading to 2,2-disubstituted 1,1difluoroalkenes. Chem. Lett. 41, 1619-1621 (2012).

20. Han, S. Y. \& Jeong, I. H. Efficient synthesis of 2,2-diaryl-1,1-difluoroethenes via consecutive cross-coupling reactions of 2,2-difluoro-1tributylstannylethenyl p-toluenesulfonate. Org. Lett. 12, 5518-5521 (2010).

21. Chelucci, G. Synthesis and metal-catalyzed reactions of gem-dihalovinyl systems. Chem. Rev. 112, 1344-1462 (2012).

22. Amii, H., Kobayashi, T., Hatamoto, Y. \& Uneyama, K. Mg0-promoted selective C-F Bond cleavage of trifluoromethyl ketones: a convenient method for the synthesis of 2,2-difluoro enol silanes. Chem. Commun. 1323-1324 (1999).

23. Burton, D. J., Yang, Z.-Y. \& Qiu, W. Fluorinated ylides and related compounds. Chem. Rev. 96, 1641-1716 (1996).

24. Lang, S. B., Wiles, R. J., Kelly, C. B. \& Molander, G. A. Photoredox generation of carbon-centered radicals enables the construction of 1,1-difluoroalkene carbonyl mimics. Angew. Chem. Int. Ed. 56, 15073-15077 (2017).

25. Xiao, T., Li, L. \& Zhou, L. Synthesis of functionalized gem-difluoroalkenes via a photocatalytic decarboxylative/defluorinative reaction. J. Org. Chem. 81 , 7908-7916 (2016).

26. Jaroschik, F. Picking one out of three: selective single $\mathrm{C}-\mathrm{F}$ activation in trifluoromethyl groups. Chem. A Eur. J. 24, 14572-14582 (2018).

27. $\mathrm{Hu}, \mathrm{M}$. et al. Copper-catalyzed gem-difluoroolefination of diazo compounds with TMSCF3 via C-F bond cleavage. J. Am. Chem. Soc. 135, 17302-17305 (2013).

28. Miura, T., Ito, Y. \& Murakami, M. Synthesis of gem-difluoroalkenes via $\beta$ fluoride elimination of organorhodium(I). Chem. Lett. 37, 1006-1007 (2008).

29. Huang, Y. \& Hayashi, T. Rhodium-catalyzed asymmetric arylation/ defluorination of 1-(trifluoromethyl)alkenes forming enantioenriched 1,1difluoroalkenes. J. Am. Chem. Soc. 138, 12340-12343 (2016).

30. Jang, Y. J., Rose, D., Mirabi, B. \& Lautens, M. Rhodium-catalyzed enantioselective defluorinative $\alpha$-arylation of secondary amides. Angew. Chem. Int. Ed. 57, 16147-16151 (2018).

31. Lu, X. et al. Nickel-catalyzed allylic defluorinative alkylation of trifluoromethyl alkenes with reductive decarboxylation of redox-active esters. Chem. Sci. 10, 809-814 (2019).

32. Lin, Z., Lan, Y. \& Wang, C. Synthesis of gem-difluoroalkenes via nickelcatalyzed reductive $\mathrm{C}-\mathrm{F}$ and $\mathrm{C}-\mathrm{O}$ bond cleavage. ACS Catal. 9, 775-780 (2019).

33. Ding, D., Lan, Y., Lin, Z. \& Wang, C. Synthesis of gem-difluoroalkenes by merging Ni-catalyzed $\mathrm{C}-\mathrm{F}$ and $\mathrm{C}-\mathrm{C}$ bond activation in cross-electrophile coupling. Org. Lett. 21, 2723-2730 (2019).

34. Chen, F., Xu, X., He, Y., Huang, G. \& Zhu, S. NiH-catalyzed migratory defluorinative cross olefin-coupling: trifluoromethyl-substituted alkenes as acceptor olefins to form gem-difluoroalkenes. Angew. Chem. Int. Ed. 132, 5436-5440 (2020).

35. Yao, C., Wang, S., Norton, J. \& Hammond, M. Catalyzing the hydrodefluorination of $\mathrm{CF} 3$-substituted alkenes by $\mathrm{PhSiH} 3$. $\mathrm{H} \bullet$ transfer from a nickel hydride. J. Am. Chem. Soc. 142, 4793-4799 (2020).
36. Nakai, T., Tanaka, K. \& Ishikawa, N. Reactions of 2,2,2-trifluoroethoxy- and 2,2,2-trifluoroethylthiobenzene with lithium dialkylamides. the formation of phenylthioynamines. Chem. Lett. 5, 1263-1266 (1976).

37. Katz, J. D., Lapointe, B. T. \& Dinsmore, C. J. Preparation of a stable trifluoroborate salt for the synthesis of 1-aryl-2,2-difluoro-enolethers and/or 2,2-difluoro-1-aryl-ketones via palladium-mediated cross-coupling. J. Org. Chem. 74, 8866-8869 (2009).

38. Bégué, J. \& Bonnet-Delpon, D. Antimalarial Fluoroartemisinins: Increased Metabolic and Chemical Stability. In Fluorine in Medicinal Chemistry and Chemical Biology, Ojima, I., Ed. John Wiley \& Sons Ltd.: UK, 2009; pp 141-163.

39. Sandler, A. \& Ettinger, D. S. Gemcitabine: single-agent and combination therapy in non-small cell lung cancer. Oncologist 4, 241-251 (1999).

40. Lacy, B. E. \& Levy, L. C. Lubiprostone: a novel treatment for chronic constipation. Clin. Inter. Aging 3, 357-364 (2008).

41. Takagi, Y. et al. Pharmacological characteristics of AFP-168 (Tafluprost), a new prostanoid fp receptor agonist, as an ocular hypotensive drug. Exp. Eye Res. 78, 767-776 (2004).

42. Rosen, B. M. et al. Nickel-catalyzed cross-couplings involving carbon-oxygen bonds. Chem. Rev. 111, 1346-1416 (2011).

43. Guo, L. \& Rueping, M. Decarbonylative cross-couplings: nickel catalyzed functional group interconversion strategies for the construction of complex organic molecules. Acc. Chem. Res. 51, 1185-1195 (2018).

44. Quasdorf, K. W., Riener, M., Petrova, K. V. \& Garg, N. K. Suzuki-Miyaura coupling of aryl carbamates, carbonates, and sulfamates. J. Am. Chem. Soc. 131, 17748-17749 (2009).

45. Barth, E. L. et al. Bis(dialkylphosphino)ferrocene-ligated nickel(II) precatalysts for suzuki-miyaura reactions of aryl carbonates. Organometallics 38, 3377-3387 (2019)

46. Somerville, R. J., Hale, L. V. A., Gómez-Bengoa, E., Burés, J. \& Martin, R Intermediacy of $\mathrm{Ni}-\mathrm{Ni}$ species in $\mathrm{sp} 2 \mathrm{C}-\mathrm{O}$ bond cleavage of aryl esters: relevance in catalytic C-Si bond formation. J. Am. Chem. Soc. 140, 8771-8780 (2018).

47. Guan, B.-T., Wang, Y., Li, B.-J., Yu, D.-G. \& Shi, Z.-J. Biaryl construction via $\mathrm{Ni}$-catalyzed $\mathrm{C}-\mathrm{O}$ activation of phenolic carboxylates. J. Am. Chem. Soc. 130, 14468-14470 (2008)

48. Nishizawa, A. et al. Nickel-catalyzed decarboxylation of aryl carbamates for converting phenols into aromatic amines. J. Am. Chem. Soc. 141, 7261-7265 (2019).

49. Mesganaw, T. et al. Nickel-catalyzed amination of aryl carbamates and sequential site-selective cross-couplings. Chem. Sci. 2, 1766-1771 (2011).

50. Sun, C.-L. et al. Construction of polysubstituted olefins through Ni-catalyzed direct activation of alkenyl C-O of substituted alkenyl acetates. Chem. A Eur. J. 16, 5844-5847 (2010).

51. Tasker, S. Z., Standley, E. A. \& Jamison, T. F. Recent advances in homogeneous nickel catalysis. Nature 509, 299-309 (2014).

52. Muto, K., Yamaguchi, J., Lei, A. \& Itami, K. Isolation, structure, and reactivity of an arylnickel(II) pivalate complex in catalytic C-H/C-O biaryl coupling. J. Am. Chem. Soc. 135, 16384-16387 (2013).

53. Diccianni, J. B. \& Diao, T. Mechanisms of nickel-catalyzed cross-coupling reactions. Trends Chem. 1, 830-844 (2019).

54. Malapit, C. A., Bour, J. R., Brigham, C. E. \& Sanford, M. S. Base-free nickel catalysed decarbonylative suzuki-miyaura coupling of acid fluorides. Nature 563, 100-104 (2018).

\section{Acknowledgements}

We acknowledge the financial support of The Hong Kong Research Grants Council (153037/14P, 153152/16P, 153023/17P, 153017/19P, and C5023-14G). Dr. Bingnan Du and Dr. Chun-Ming Chan thanks The State Key Laboratory for Chemical Biology and Drug Discovery for the generous support of the Postdoctoral Fellowship.

\section{Author contributions}

B.D. performed the experiments. W.-Y.Y. conceived, directed the project, and wrote the paper. C.-M.C. engaged in revision of the manuscript, mechanistic studies, revamping the data, and graphical presentation of the manuscript and revised the Supplementary Information. P.-Y.L. and L.-H.C. prepared and organized physical characterization data involved in discussion of mechanism, purification of substrates and preparation of the initial draft of the manuscript. X.X. and Z.L. conducted the density functional theory calculations.

\section{Competing interests}

The authors declare no competing interests. 


\section{Additional information}

Supplementary information is available for this paper at https://doi.org/10.1038/s41467020-20725-9.

Correspondence and requests for materials should be addressed to Z.L. or W.-Y.Y.

Peer review information Nature Communications thanks $\mathrm{Xi}$ Lu and the other, anonymous, reviewer(s) for their contribution to the peer review of this work. Peer reviewer reports are available.

Reprints and permission information is available at http://www.nature.com/reprints

Publisher's note Springer Nature remains neutral with regard to jurisdictional claims in published maps and institutional affiliations. (c) (i) Open Access This article is licensed under a Creative Commons Attribution 4.0 International License, which permits use, sharing, adaptation, distribution and reproduction in any medium or format, as long as you give appropriate credit to the original author(s) and the source, provide a link to the Creative Commons license, and indicate if changes were made. The images or other third party material in this article are included in the article's Creative Commons license, unless indicated otherwise in a credit line to the material. If material is not included in the article's Creative Commons license and your intended use is not permitted by statutory regulation or exceeds the permitted use, you will need to obtain permission directly from the copyright holder. To view a copy of this license, visit http://creativecommons.org/ licenses/by/4.0/.

(C) The Author(s) 2021 